\title{
TRIP GENERATION AND TOUR DISTRIBUTION OF PUBLIC TRANSPORT TRIPS IN THE CITY OF SLAVONSKI BROD
}

\author{
DOI: 10.18485/arh_pt.2020.7.ch58
}

\author{
_ Ljupko Šimunović \\ Full professor, Faculty of Transport and Traffic \\ Sciences, Vukelićeva 4, ljsimunovic@fpz.unizg.hr

\section{_ Julijan Jurak} \\ Research associate, Faculty of Transport and \\ Traffic Sciences, Vukelićeva 4, jjurak@fpz.unizg.hr
}

\section{Božo Radulović}

Research associate, Faculty of Transport and

Traffic Sciences, Vukelićeva 4, bradulovic@fpz.unizg.hr

\author{
_ Matija Sikirić \\ Research associate, Faculty of Transport and \\ Traffic Sciences, Vukelićeva 4, msikiric@fpz.unizg.hr
}

\section{ABSTRACT}

Trip generation and trip distribution are the first steps in conventional four-step travel demand modelling. Four-step travel demand model is the most used methodology for creating validated data regarding travel demand and traffic flows in a defined area, territory or city. Trip generation calculates number of trips that are produced or attracted from specific area or a territory, while trip distribution determines how many trips are conducted from one area to another (or zone). Slavonski Brod is one of the largest cities (7th) in the Republic of Croatia and it is the centre of Brodsko-posavska County. Public transport in the City of Slavonski Brod is organized by a private operator with eight defined bus lines and with more than 70 departure from 5AM to 11PM during a characteristic workday. Used data for determining trip generation and trip distribution was collected during a questionnaire survey conducted during the project development of the Sustainable Urban Mobility Plan of the City Slavonski Brod. Goal of paper is to detect how household characteristics influences trip rate values and origin-destination matrices between various areas of the City for trips in the public transport. The paper will consist of an introduction, literature overview, methodology of data collection, results of trip production, trip attraction and origin-destination matrix, discussion about calculated vales and conclusion.

KEYWORDS _ urban mobility, transport and traffic solutions

\section{INTRODUCTION}

Trip generation and distribution is the first step in a four-step transport demand model methodology. Trip generation is the number of trips that occur or are attracted to specific zones and areas. Trip distribution represents the number of trips between two specific zones or areas. The city of Slavonski Brod is the centre of the Brodsko-posavska County and one of the largest cities in the Republic of Croatia. According to the 2011 census report, there were an estimated 60,000 inhabitants. 
Passenger transportation is performed by Terzić bus d.o.o. on eight lines according to the contract between the city and the transportation operator. There are 72 departures on eight lines during a typical business day. One of the tasks of the Sustainable Urban Mobility Plan of the Slavonski Brod Urban Area was to analyse the current state of mobility. The analysis entailed counting passengers at all departures and conducting a survey in public transport vehicles and households. Determining the impact of household characteristics on the number of trips and the trip distribution is a crucial part of the work. Household characteristics were determined through household surveys. After determing the number of trips and their distribution, conclusions were drawn as how household characteristics influences trip rate values and origin-destination matrices between various areas of the City for trips made by public transport.

\section{LITERATURE OVERVIEW}

The conventional four-step transportation planning model consists of 4 phases: trip generation; trip distribution; modal split; and traffic assignment (Easa, 1993). According to Meurs, 1990., trip generation models are often used to forecast future travel demands in specific regions, given population characteristics such as household size and composition, income, car ownership and sometimes residential descriptors, such as density and network connectivity of the zones where the household is situated. In order to assess the land use policy implications, trip generation rates are essential knowledge for both planners and engineers working in the field of town planning and transportation (Pitisiava-Latinopoulou, Tsohos, and Basbas, 2001.). The objective of trip generation is to estimate the number of trips originated in each zone within the study area, which it is usually correlated to the socioeconomic characteristics of the resident population in that zone (Ortuzar, 2000).

Trip distribution is a fundamental element of short-range analysis and long-range transportation planning (Easa, 1993.), but can also be used for large scale development projects, community level planning, and corridor studies (Mcguckin, 2015.). There are two different approaches to trip generation, micro, ie. site impact studies, and macro, ie. regional planning studies. In terms of data collection, one approach relies on direct observation and counts of traffic entering and leaving specific land uses while the other relies primarily on person-trip information obtained in regional origin-destination (O-D) surveys (Mcguckin, 2015.). The decision of an individual in choosing a transportation mode to be used for his/her daily trips is related to several characteristics. The trips attractors (Aparecido, Pongitori, 2015.) can be related to the characteristics of individuals (sex, age, income, educational level etc.), characteristics of the available transportation mode (cost, travel time, comfort, safety etc.), characteristics of the" trip per se" (length, schedule, motive etc.), and to the characteristics of the urban environment (accessibility, topography, land use, urban density etc.). Trip distribution consists of the following elements (Easa, 1993.): preparing input data; selecting a trip distribution model; calibrating the model; validating the model; and forecasting. Trip distribution is mainly affected by the purpose of the trip. The weight of the destination zones is different from purpose to purpose and the attractivity of the zones are influenced by (accepted) travel time and distance (impedance) of the persons doing a trip. As it is common praxis, the trip distribution model considers the weight of each zone as well as the impedance between zones (Berki, Monigl, 2017.). For each zone in the study area it is necessary to determine the area covered by each land-use to estimate the trips to and from that zone (Amavi, Luigi, Ibeas, 2014.).

The operation of the transport model requires the origin-destination trip vectors for each analysis period, classified by trip purpose and demand category, as input data. Those trip vectors are estimated through the generation/attraction models (Amavi, Luigi, Ibeas, 2014.). The base-year trip matrix is generally composed of three types of trips: internal trips, external-internal trips, and external trips (Easa, 1993.). O-D surveys are the most frequently used method of collecting travel pattern data, with the advantage in locating both ends of the trip. Vehicle or person counts obtained from specific locations are the basis for trip generation rates used in site planning and site impact evaluation studies (Mcguckin, 2015.). 


\section{METHODOLOGY OF DATA COLLECTION}

The data used in the paper is collected during the analysis of the current state of mobility and the transport system in the urban area of Slavonski Brod. The current mobility situation analysis consisted of data collected by assessing the city's traffic flows, passenger counting in public transport vehicles, and surveying households. The data collected by counting made it possible to calibrate and evaluate the results. Passenger surveys were conducted during one characteristic day on all departures of public passenger transport. Household surveys were conducted throughout the administrative area of the City of Slavonski Brod. The methodology for processing the results consisted of data collected from household and passenger surveys. The collected data were processed in the MS excel software tools, QGIS 3.4. and PTV Visum. The data were processed according to the basic characteristics of the population: number, age and financial possibilities. The production and attraction of public transport passenger journeys are calculated from household survey data, while the origin-destination travel matrix is calculated from the passenger survey.

\section{TRIP GENERATION OF PUBLIC TRANSPORT TRIPS}

Generating trips in traffic planning is one of the first steps of the four-step concept of creating a traffic demand model. Traffic demand is the number of trips attributed to a given traffic network in a unit of time. In the literature, four-step concepts take two time periods, the whole day and the peak period. The peak period is the hour or two-hour period during which demand for a mode of travel is at its highest. By defining the transport network, it is necessary to define a set of spatial units (hereinafter TAZs) in the observed area. The size and number of TAZs depends on the detail of traffic modelling, number of households, population density, spatial and economic characteristics of the coverage area. The paper analyses the administrative area of the City of Slavonski Brod, where, according to the listed characteristics, approximately 90 TAZs were determined. The household survey was conducted according to TAZs where it focused on the equal representation of the sample from each individual TAZ. The data collected through the survey is sublimated into the mode of travel distribution. Following data influences the trip generation and thus the way in which trips are distributed: the age structure of respondents, the working status of residents and the number of passengers arriving and departing at all stops of public passenger transport.

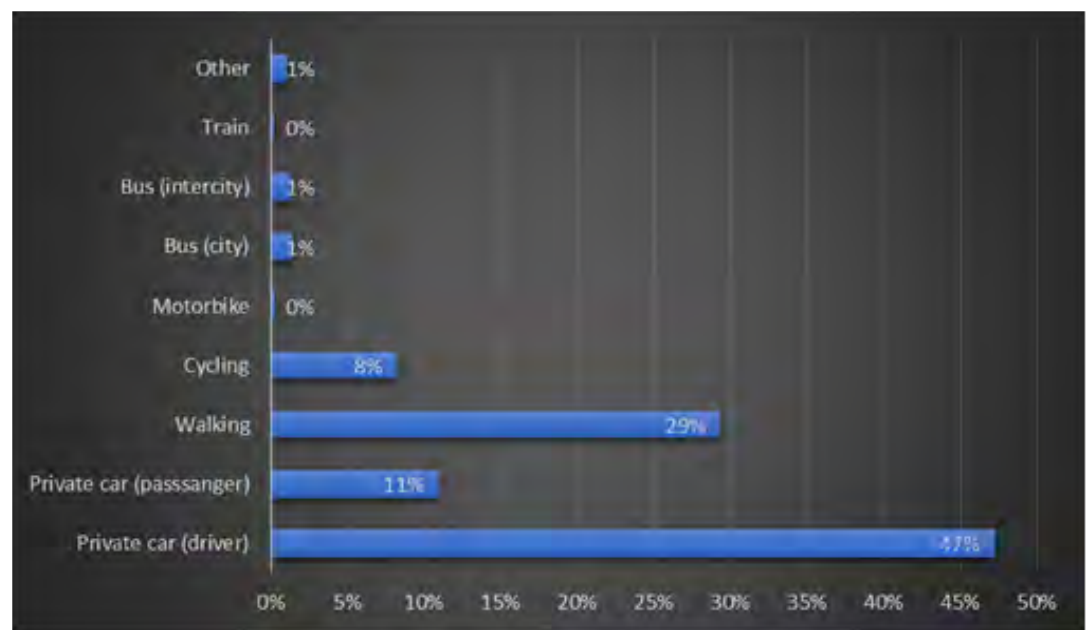

_ Figure 2 Working status of the respondents 
Figure 1 Modal share of travel for the City of Slavonski Brod

Figure 1 shows the modal share of trips in the area of the City of Slavonski Brod. Observing the total number of trips, only $3 \%$ of passengers use public transport, of which $1.4 \%$ of respondents use daily commuter transport (the remainder belongs to rail and county bus passenger transport). The chart also shows that $60 \%$ of respondents use a passenger car every day as a driver or passenger. Such distribution suggests poorly organized and efficient urban passenger transport.

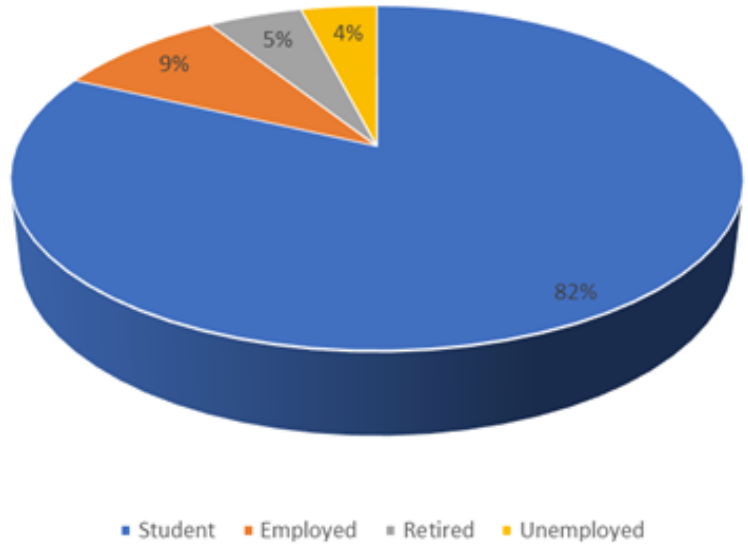

_ Figure 2 Working status of the respondents

The passenger survey showed the following data:

_ More than 4/5 of all travellers are high school or college students;

_ A tenth of all passengers are employed persons;

_ More than $2 / 3$ of all passengers are 18 or under 18 years of age;

_ Only $3 \%$ of passengers are over 65 years of age.

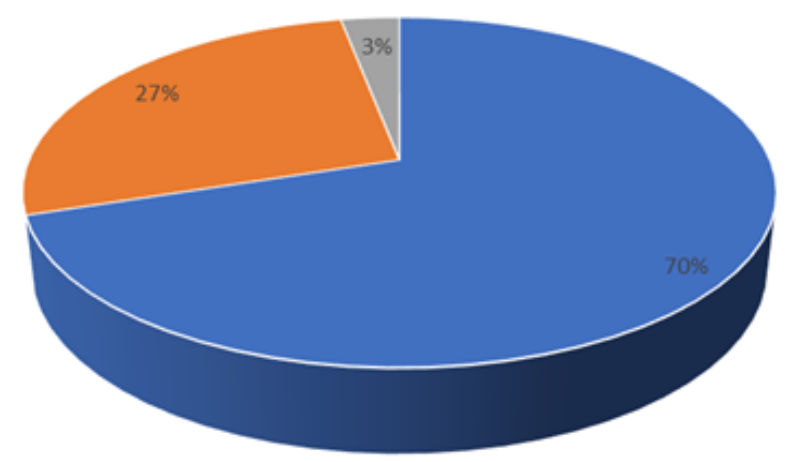

- Under 18 yeras old = Between 18 and 65 years old = Above 65 yeras

_ Figure 3 Ages of the respondents

The data suggest that the vast majority of passengers use public transport for reasons of inability to use a car or other forms of private transport (motorcycle, bicycle, etc.). The data also show that the largest number refers to persons under the age of 18 who are forced to use public transport due to school obligations (compulsory travel), although pensioners are a dominant population structure. 


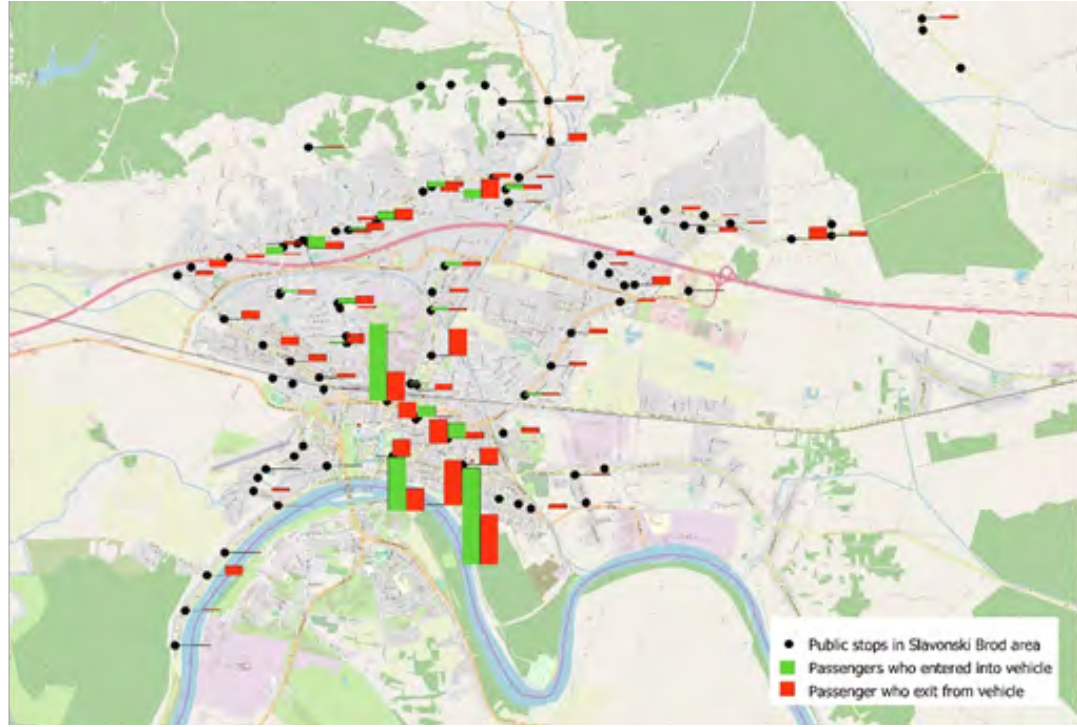

_ Figure 4 Numbers of passengers at public stops

Figure 4 shows the total number of passengers arriving and departing during a typical business day at all bus stops. Green indicates passengers entering and red passengers departing. The figure shows that most passengers arrive or departure at a small number of stops, and that these stops are located in the centre of the City of Slavonski Brod.

\section{TRIP DISTRIBUTION OF PUBLIC TRANSPORT TRIPS}

Trip distribution is the second step in the four-step concept of traffic demand. Travel distribution represents the number of trips between all zones in the observed area. By defining 90 zones when creating a traffic model, 90 pairs of journeys were created between zones for public passenger transport. The total number of trips during a typical business day is 2070 trips. By dividing this number by the number of trips, you get a ratio of 30 trips from and to each zone using public transport. By reducing the time period to the peak hour, this ratio shows an average of only 3 to 5 passengers per zone.

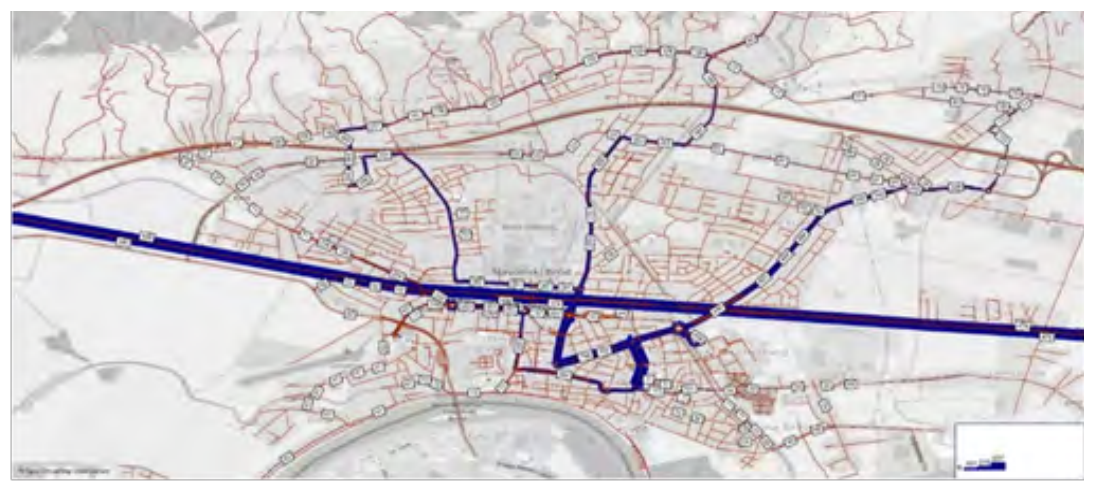

_ Figure 5 Numbers of passengers obtained from the transport model during a typical business day 
Figure 5 shows the traffic model of demand for public passenger transport in the area of the City of Slavonski Brod. The model in the figure represents the total number of trips on the public transport network during the business day. The following information can be read from the figure:

_ The busiest part of the public transport network is the downtown area around the main attractors of travel;

_ The north and north-eastern parts of the city located next to the center follow by observing the loads of public transport;

- The eastern, western and north-western parts of the city have under 100 passengers transported during the weekdays.

\section{DISCUSSION OF RESULTS}

The collected and processed data from the household survey and passenger characteristics served to create a traffic model of demand for public passenger transport in the area of the City of Slavonski Brod. The very low share of public passenger transport (below $2 \%$ of urban transport) suggests several possible reasons. The reasons are as follows: the low number of departures; the public transport fleet age; the poorly traced routes; the mismatch of all forms of public transport; poor infrastructure; insufficient number of stops; and outcomes of poor tariff policy. All these considerations have a stronghold in the passenger survey, which suggests a large number of passengers being forced to use public transport because of the inability to use their car or the distance between the source and destination of their trips. The low share of pensioners in the total number of passengers carried confirms the reasons listed above. By comparing the results of the survey and the data obtained by the transport model, a large influence of household characteristics can be determined. If the household owns a car or can use a private car, the household is not likely to use public passenger transport. When there are young people in the household who attend high school or college, the likelihood of using public transport is greatly increased, regardless of the system characteristics. Due to the extremely negative demographic picture of the population of the area and the emigration of the working population, the majority of households will be exclusively retired persons. Adapting public transport to such a structure (over 65 years of age and small financial opportunity) can result in an increase in the number of passengers and, consequently, a greater share of public transportation in the overall trip modal share.

\section{CONCLUSIONS}

Trip generation and trip distribution are the basic elements of making a quality analysis for planning both short-term and long-term measures and strategies. The development of the model can identify certain patterns of travel, as well as the shortcomings in the current mobility planning, and result in timely reactions in eliminating them. The collection of relevant data through the counting of passengers, their survey and the survey of households in the area of the City of Slavonski Brod, showed a great influence of household characteristics on travel habits. The proportion of only $1.4 \%$ of respondents using public urban passenger transport, over $80 \%$ of whom are high school or university students, suggest that all trips of the obligatory (mandatory) type of trip are completed. The passengers counting and the trip distribution showed that the largest number of inbound passengers is in the area of densely populated residential areas, while the destinations were in the areas of large attractors (school, college, hospital, market). The extremely low number of trips and the largest distribution of trips from the city centre to the outskirts of the city confirms the obligatory travel thesis. A large proportion of pensioners in the total population, and their low representation as users of public transport, are a key element in improving public transport services and adapting infrastructure.

Very close or the same level of influence of household characteristics on travel habits in similar cit- 
ies as Slavonski Brod can be detected. Similar cities can be found in this part of Europe, with similar number of inhabitants or socio-economic similarities. But there is needed to conduct research that will accept or reject that hypothesis.

\section{REFERENCES}

- Alexandre, Amavi, Juan, Romero, Luigi, Dell'Olio, and Angel, Ibeas. Advanced Trip Generation/Attraction Models. Procedia - Social and Behavioral Sciences 160. 2014. pp. 430 - 439.

- H., Meurs. Trip generation models with permanent unobserved effects. Transport Research-B, Vo1.24B. No.2. 1990. pp. 145-158.

_ J.D., Ortuzar. Modelos de demanda de transporte. Ediciones Alfaomega. Santiago. 2000.

- José, Aparecido, and Caroline, Pongitori. Characteristics of the Trips Generated by a Trip Generation HUB. 10th International Conference on Coputers in Urban Planning and Urban Management. 2015.

- M., Pitisiava-Latinopoulou, G., Tsohos, and S., Basbas Trip generation rates and land use - transport planning in urban environment. Transactions on the Built Environment vol. 52. 2001. ISSN 1743-3509

- Nancy, Mcguckin. An Overview of Trip Generation. Trip Generation Discussion Working Paper. 2015.

- Said M., Easa. Urban Trip Distribution in Practice I: Conventional Analysis. Journal of Transportation Engineering 119. 1993. pp. 793-815

_ Zsolt. Berki, and Janos, Monigl. Trip generation and distribution modelling in Budapest. Transportation Research Procedia. 20th EURO Working Group on Transportation Meeting, EWGT 2017. Budapest. 2017.

_ Faculty of Transport and Traffic Sciences. Sustainable Urban Mobility Plan of urban area Slavonski Brod - Mobility analysis report. Slavonski Brod. 2019 